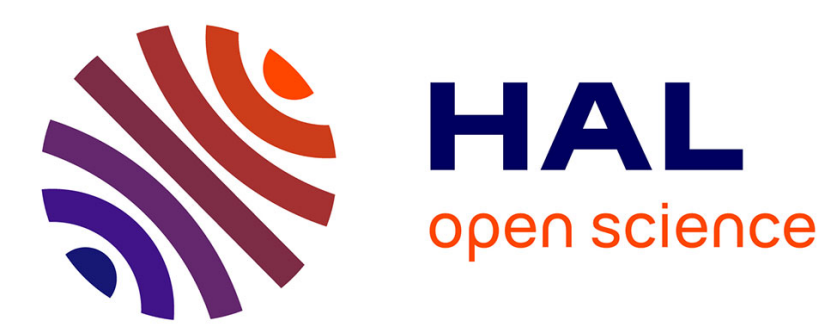

\title{
Structure and function of the coupling-factor of photosphorylation
}

\author{
J. M. Galmiche, G. Girault, C. Lemaire
}

\section{To cite this version:}

J. M. Galmiche, G. Girault, C. Lemaire. Structure and function of the coupling-factor of photosphorylation. Photochemistry and Photobiology, 1985, 41 (6), pp.707-713. 10.1111/j.17511097.1985.tb03626.x . cea-02890730

\section{HAL Id: cea-02890730 https://hal-cea.archives-ouvertes.fr/cea-02890730}

Submitted on 6 Jul 2020

HAL is a multi-disciplinary open access archive for the deposit and dissemination of scientific research documents, whether they are published or not. The documents may come from teaching and research institutions in France or abroad, or from public or private research centers.
L'archive ouverte pluridisciplinaire HAL, est destinée au dépôt et à la diffusion de documents scientifiques de niveau recherche, publiés ou non, émanant des établissements d'enseignement et de recherche français ou étrangers, des laboratoires publics ou privés. 


\section{YEARLY REVIEW}

\section{STRUCTURE AND FUNCTION OF THE COUPLING-FACTOR OF PHOTOPHOSPHORYLATION}

This topic deals with the catalytic part of the ATPsynthase present in the thylakoids from higher plants, green algae, photosynthetic bacteria and cyanobacteria. We also refer to some specific results obtained with proton-ATPase from Escherichia coli, thermophilic bacterium $\mathrm{PS}_{3}$ and mitochondria. The most important change in this field is the very fast development of our knowledge of the primary structure of the constituents of the ATP-synthase.

\section{Molecular weight and subunit stoichiometry of the coupling-factor}

In higher plants, ATP-synthase is mostly present in stroma lamellae (Faludi-Daniel et al., 1983). The enzyme is formed of the coupling-factor, $\mathrm{CF}_{1}$ or $\mathrm{F}_{1}$, localized in the outer part of the thylakoids and of the $\mathrm{CF}_{0}$ or $\mathrm{F}_{0}$, hydrophobic part, buried in the membrane. The $F_{1}$ is composed of 5 subunits, $\alpha-\beta-\gamma-\delta-\epsilon$, and $F_{0}$ of 3, I-II-III (Alt et al., 1983). Chloroplast genes coding for the subunits $\alpha, \beta$, and III are photogenes (de Heij et al., 1984; Rodermel and Bogorad, 1985). A similar $F_{1}$ has been also extracted and purified from cyanobacteria, Synechococcus (Lubberdings et al., 1983; Van Walraven et al., 1984) and Mastigocladus laminosus (Frei et al., 1984) and photosynthetic bacteria, Rhodospirillum rubrum (Khananshvili and Gromet-Elhanan, 1982) and Rhodopseudomonas sphaeroides (Müller et al., 1983).

$\beta$ Subunits from $F_{1}$ of different organisms present a high homology (Nelson and Cidon, 1984) and generally have a molecular weight lower than that of the corresponding subunit $\alpha$ (Merchant and Selman, 1983). However, in Dunaliella order of migration of subunits $\alpha$ and $\beta$ in polyacrylamide gel electrophoresis, is inversed (Selman-Reimer et al., 1984). The recent determinations give a molecular weight of $400 \mathrm{kD}$, instead of $325 \mathrm{kD}$, for $\mathrm{CF}_{1}$ in spinach (Moroney et al., 1983) and Chlamydomonas reinhardii (Merchant et al., 1983). These results are consistent with a stoichiometry $\alpha_{3} \beta_{3} \gamma \delta \in$ which is in accord with the analyses of uniformly labelled $\left[{ }^{14} \mathrm{C}\right] \mathrm{CF}_{1}$ (Merchant et al., 1983; Süss and Manteuffel, 1983). The subunit $\delta$ is easily lost during $\mathrm{CF}_{1}$ purification (Moase and Green, 1981; Finel et

*To whom correspondence should be addressed. al., 1984) and Berzborn et al. (1984) propose that the true stoichiometry is $3 \delta$ per $C F_{1}$. Electron microscopy of negative stained $\mathrm{CF}_{1}$ exhibits a six-fold symmetry (Moase and Green, 1981; Akey et al., 1983) or a three-fold symmetry when $\alpha$ subunits have bound a monoclonal specific antibody (Tiedge et al., 1984), indicating a stoichiometry $\alpha_{3} \beta_{3}$.

\section{Primary structure and organization of the coupling-factor}

Determination of the primary structure of the ATP-synthase begins with the analysis of the DNA sequence of the genes coding for the different subunits in the following organisms. Subunits $\alpha, \beta$ and $\epsilon$ are sequenced in tobacco (Deno et al., 1983; Deno and Sugiura, 1984; Shinozaki et al., 1983), subunits $\beta$ and $\epsilon$ in maize (Krebbers et al., 1982), subunits $\beta$ and $\epsilon$ in spinach (Zurawski et al., 1982), subunits $\beta$ and $\epsilon$ in barley (Zurawski and Clegg, 1984). Genes for the subunits $\alpha, \beta$ and $\epsilon$ are located in pea and will be soon sequenced (Huttly and Gray, 1984). Subunit $\alpha$ has been partially sequenced in Chlamydomonas reinhardii (Hallick, 1984) and genes coding for subunits $\alpha, \beta$ and $\epsilon$ have been localized (Woessner et al., 1984). The five subunits of $\mathrm{F}_{1}$ are sequenced in Rhodopseudomonas blastica (Tybulewicz et al., 1984).

The secondary structure of each subunit of the ATP-synthase from Escherichia coli has been inferred from the amino acid sequence. Organization of the peptidic chains in the membrane has also been proposed from the calculated hydropathy of the amino acid sequences (Hoppe and Sebald, 1984, Walker et al., 1984). Comparison of the sequences in ATP-synthase from Escherichia coli and photosynthetic organisms allow the prediction of arrangements of the peptidic chains for the last organisms. Sixty-six amino acid residues (Deno and Sugiura, 1984) are identical along the $\alpha$ and $\beta$ subunits from tobacco and are positioned in sequences which participate in the binding of nucleotides in other nucleotide-binding enzymes (Kanazawa et al., 1982). The percentage of homologous amino acid residues of the different subunits $\beta$ is around $90 \%$ (Shinozaki et al., 1983), corresponding to a conservation of their secondary structure throughout the different organisms.

Organization of the subunits has been investigated 
by chemical cross-linking (Rott and Nelson, 1984) and accessibility to the specific antibodies (KleinHitpass and Berzborn, 1984). Subunits $\alpha$ and $\beta$ must be arranged alternately in an hexameric figure which is stabilized by the subunit $\gamma$ forming the core of the complex. Subunits I and II are in contact with subunits $\delta$ and $\epsilon$, suggesting their role in the attachment of $F_{1}$ to $F_{0}$.

Physical methods have been used for studying the general organization of the ATP-synthase. Small angle $X$-ray scattering has been applied in thermophilic bacterium $\mathrm{PS}_{3}$ (Furuno et al., 1983) and mitochondria (Amzel et al., 1982). Neutron small angle scattering has been used with the $F_{1}-F_{0}$ complex from Rhodospirillum rubrum (Nawroth et $a l ., 1983$ ) and with the $F_{1}$ from Escherichia coli (Satre and Zaccai, 1979). Circular dichroism gives some information on the conformation changes of spinach $\mathrm{CF}_{1}$ by fixation of the substrates (Younis et al., 1983). Fluorescent probes have been widely used (Pick and Finel, 1983) and allow determinations of the distances between the different sites on $\mathrm{CF}_{1}$ (Cerione et al., 1983, Snyder and Hammes, 1984).

\section{Properties of the different subunits}

In the $F_{1}$ part, subunits $\alpha$ and $\beta$ bind the nucleotides (Deno and Sugiura, 1984; Kanazawa et $a l,, 1982)$. Subunit $\beta$ is thought to bear the catalytic sites. Some specific sites of this subunit have been mapped. DCCD binding-sites in thermophilic bacterium $\mathrm{PS}_{3}$ and in Escherichia coli or mitochondria correspond respectively to the glutamic acid 204 and 215 in the subunit $\beta$ from the spinach chloroplast ATP-synthase (Yoshida and Allison, 1983). The photo-affinity probe, 8-azido ATP, binds on 3 amino acid residues of the subunit $\beta$ in mitochondria (Hollemans et al., 1983) corresponding to the lysine 317 , isoleucine 321 and tyrosine 328 of the homologous subunit in spinach, in a part of the peptidic chain called Rossmann fold, which is essential for the catalytic activity (Kanazawa et al., 1983-a). In photosynthetic organisms the photoaffinity analogues of the nucleotides label subunits $\alpha$ and $\beta$ or $\beta$ only following the favored conformation "syn" or "anti" of the probe (Czarnecki et al., 1982, Czarnecki et al., 1983, Abbott et al., 1984). The conformation "anti" is required for nucleotides to be a good substrate (Czarnecki, 1984).

Subunit $\gamma$ is necessary for the reconstituted $\alpha-\beta$ complex to elicit an ATP-ase activity in Escherichia coli (Kanazawa et al., 1983b) and Thermophilic bacterium $\mathrm{PS}_{3}$ (Kagawa et al., 1984). In photosynthetic organisms such a reconstitution from isolated subunits is not achieved. In chromatophores of Rhodospirillum rubrum the subunit $\gamma$ is necessary for photophosphorylation (Khananshvili and Gromet-Elhanan, 1982). In $\mathrm{CF}_{1}$ from spinach subunit $\gamma$ bears a disulfide bond $S_{1}-S_{2}$ and two sulfhydryl residues $S_{3}, S_{4}$ (Nalin and McCarty, 1984, Moroney et al., 1984, Ketcham et al., 1984). $S_{3}$ and
$\mathrm{S}_{4}$, oxidized to a disulfide bond or cross-linked, induce a proton leak through the chloroplast membrane indicating the subuit $\gamma$ behaves like a proton gate. Sulfhydryl group $S_{3}$ is essential for ATPsynthase activity and is the only SH group found in all the subunits $\gamma$ from the different organisms, especially from Rhodopseudomonas blastica (Tybulewicz et al., 1984) and corresponds to the cystein 88 in Escherichia coli $y$ subunits. Reduction of the disulfide bond $S_{1}-S_{2}$ induces ATP-ase activity and is not found in the subunit $\gamma$ from mitochondria or Escherichia coli, where there is no regulation of the ATPase activity. Subunit $\gamma$ forms the core of the $\alpha \beta$ complex and regulates its activity by inducedchanges of its conformation.

Subunit $\delta$ has been proposed for a long time as the anchorage point between $F_{1}$ and $F_{0}$. This proposal has been challenged by Berzborn et al. (1984) and Patrie and McCarty (1984). Subunit $\delta$ seems to be mostly necessary to prevent non-productive leak of protons through $\mathrm{CF}_{0}$ and not to be required for photophosphorylation itself.

Subunit $\epsilon$ is an ATPase inhibitor but for the isolated $\mathrm{CF}_{1}$ only (Finel et al., 1984; Richter et al., 1984). This $\mathrm{CF}_{1}$ without subunit $\epsilon$ is a permanently $\mathrm{Ca}^{2+}$ ATPase, inhibited by subunit $\epsilon$ addition, which does not recouple $\mathrm{CF}_{1}$ depleted thylakoids unless subunit $\epsilon$ is added (Richter et al., 1984). Subunit $\epsilon$ is not required for binding $\mathrm{CF}_{1}$ to the membrane, but its presence prevents, as subunit $\delta$ does, ineffective leak of protons through $\mathrm{CF}_{0}$.

\section{Coupling-factor activation}

In soluble $\mathrm{CF}_{1}$, subunit $\epsilon$ is the internal inhibitor of the ATPase activity. The physical treatments which induce the ATPase activity (Anthon and Jagendorf, $1983,1984)$ release the subunit $\epsilon$ from the core of the enzyme. Heat treatment displaces subunit $\epsilon$ without changing the state of the disulfide bridge (Patrie and McCarty, 1984), as does ethanol treatment (Richter et al., 1984) and anion-exchange HPLC (Finel et al., 1984). The chemical treatments which induce ATPase activity do not release subunit $\epsilon$. Thiol activation correlates with the reduction of the disulfide bridge, $S_{1}-S_{2}$, in subunit $\gamma$ and protease activation with the cleavage of subunit $\alpha$ (Nalin and McCarty, 1984; Ketcham et al., 1984).

With $\mathrm{CF}_{1}-\mathrm{CF}_{0}$ in the membrane we observe a dual action: the build-up of a $\Delta \tilde{\mu} \mathrm{H}$ across the membrane induces a conformational change in the $\mathrm{CF}_{1}$ part of the ATPase demasking the thiol residue $S_{3}$ and making the disulfide bridge $S_{1}-S_{2}$ accessible to the second action, reductive breakage of this $S_{1}-S_{2}$ bond. Conversely these thiol groups $S_{1}, S_{2}$ are protected against oxidative reagents in the presence of the $\Delta \bar{\mu} H$ and become exposed when $\Delta \bar{\mu} H$ is cancelled (Shahak, 1985). These two processes induce the ATPase activation. This is reminiscent of the dual action of the heat and disulfide reducing agents on the activation of the ATPase activity in isolated $\mathrm{CF}_{1}$ 
(Nalin and McCarty, 1984). In chloroplasts the disulfide reducing agent is a thioredoxin (Mills and Mitchell, 1984). Gräber et al. (1984), Rumberg and Becher (1984) and Mills and Mitchell (1984) propose that the activation of the ATPase is caused by the protonation and deprotonation of the parts of the ATPase respectively, turned to the outside and the inside of the thylakoids. With $\mathrm{CF}_{1}-\mathrm{CF}_{0}$ reconstituted in liposomes, the ATPase as well as the ATPsynthase activities depend on the nature of the phospholipids used (Pick et al., 1984). In photosynthetic bacteria, activation of the ATPase seems to present a different mechanism (Casadio and Melandri, 1984). The common point is that activation of the enzyme is valuable as well for dark ATP hydrolysis as for light-dependent ATP synthesis (Vallejos et al., 1983).

\section{ATP synthesis and proton flux}

It is clear that ATP synthesis is coupled to a proton flux from inside to outside of the thylakoids and depends on the value of the $\Delta \bar{\mu} \mathrm{H}$ across the membrane.

The ratio $\mathrm{H}^{+}$to ATP has been reported equal to 3, during ATP synthesis in chloroplasts (Davenport and McCarty, 1984; Gräber et al., 1984; Rumberg and Becher, 1984) and with $\mathrm{CF}_{1}-\mathrm{CF}_{0}$ reconstituted in liposomes (Dewey and Hammes, 1981), but ratios between 2 and 8 , following the nature of the lipids used, have been found in liposomes where bacteriorhodopsin and yeast mitochondria ATP-synthase have been reconstituted (Van der Bend et al., 1984). Moreover, during flash-induced ATP synthesis in pea chloroplasts, we found a ratio $\mathrm{H}^{+}$/ATP of between 2 and 4 , following the state of the chloroplasts (Lemaire $e t$ al., 1984).

Several arguments have been given in favor of a localized $\Delta \tilde{\mu} H$ (Haraux and de Kouchkovsky, 1983). Double inhibitor titrations experiments (Hitchens and Kell, 1983) argue for a localized $\Delta \bar{\mu} H$ and based on these experiments Westerhoff $e t$ al. (1984) propose a "mosaic coupling" in chromatophores. Yet we have to remark that not only some results must be artefactual (Cotton and Jackson, 1983) but also the principle of the double inhibitor titration is criticizable (O'Shea and Thelen, 1984). All the protons moving in thylakoids do not have the same efficiency for ATP synthesis (Hangarter and Good, 1984; Flores and Ort, 1984), but Davenport and McCarty (1984) do not find any differences for protons generated by the two photosystems excitation. Nevertheless many experimental results are interpreted by the existence of certain domains in the thylakoids, where the protons are out of equilibrium with the bulk phase (Dilley and Schreiber, 1984; Laszlo et al., 1984; Hong and Junge, 1984; Junge et al., 1984; Schreiber, 1984a,b).

The relation between ATP synthesis and proton flux is an open question, which would be settled only by experiments on a molecular basis. In this line
Kagawa (1984) presents a model for the proton motive ATP synthesis based on an acid-base cluster hypothesis.

\section{Nucleotide binding-sites/enzymatic mechanism and ATP synthesis}

The $\mathrm{CF}_{1}$ contains two categories of nucleotide binding-sites: "tight sites" with a $K_{\mathrm{D}}$ of $10^{-7} M$ or less and "loose sites" with a higher $K_{\mathrm{D}}$ (Strotmann, 1985). With the membrane bound $C_{1}$, affinities are modified by interaction of the enzyme with the membrane of the thylakoids and by energization by light and the resulting proton motive force. It results that a so called "tight site" on isolated $\mathrm{CF}_{1}$ can become a "loose site" on membrane bound $\mathrm{CF}_{1}$ and activation of the ATP-synthase in the thylakoids is well reported by its ability to exchange its bound nucleotides with the nucleotides free in the medium.

Three nucleotide binding-sites are most often found with isolated $\mathrm{CF}_{1}$ (Strotmann, 1985). Six binding-sites for ATP, two per purified $\beta$ subunit, (Gromet-Elhanan and Khananshvili, 1984) or ADP (Khananshvili and Gromet-Elhanan, 1984c) are characterized on the $\beta$ subunits removed from the Rhodospirillum rubrum membrane bound ATPsynthase. The intrinsic content of purified $\mathrm{CF}_{1}$, even after treatment to remove residual $A D P$, is still 0.5 to 1.0 ADP per $\mathrm{CF}_{1}$ (Girault et al., 1982). $\mathrm{CF}_{1}-\mathrm{CF}_{0}$ contains at least $1 \mathrm{ADP}$ and $1 \mathrm{ATP}$ per mol (Cerione and Hammes, 1981). Illuminated thylakoids, in the presence of $\left[{ }^{14} \mathrm{C}\right] \mathrm{ADP}$ bind 0.85 (Schumann, 1984) to $1.3 \mathrm{~mol}\left[{ }^{14} \mathrm{C}\right]$ ADP (Bickel-Sandkötter, 1983) per mol of $\mathrm{CF}_{1}$ under steady-state conditions. Beside those radioactive nucleotides, some non-exchangeable and non-radioactive nucleotides should be present.

Part of the bound nucleotides in the chloroplastATPase can be exchanged while the other part is not. At high medium ADP concentration, in the light, about $35 \%$ of the total enzyme molecules contain a loosely bound ADP and $65 \%$ a tightly bound ADP, while almost none of the enzyme molecules are free from ADP (Schumann, 1984). On the isolated CF , one ADP is difficult to exchange and two ADP or ATP are more easily exchangeable (Girault et al., 1982). The magnesium is necessary for binding of one of the two ATP (Bruist and Hammes, 1981) or for the two (Girault et al., 1982).

Localization of the nucleotides binding sites. After tight binding of 2-azido[ $\left[{ }^{32} \mathrm{P}\right] \mathrm{ADP}, 1.4 \mathrm{nmol} / \mathrm{mg}$ of chlorophyll, (Czarnecki et al., 1983) or 2-azido $\left.{ }^{32} \mathrm{P}\right] \mathrm{ATP}$, resulting from phosphorylation of 2-azido ADP, the radioactivity covalently bound was recovered on identical portions of the $\beta$ subunit polypeptide (Abbot et al., 1984).

With $\left[{ }^{14} \mathrm{C}\right] 8$-azido ATP $\left(8-\mathrm{N}_{3}\right.$-ATP) the $\alpha$ subunits of thermophilic bacterium $\mathrm{PS}_{3}$ were preferentially labelled $\left(0.8-0.9 \mathrm{~mol} 8-\mathrm{N}_{3}-\mathrm{ATP} / \mathrm{CF}_{1}, \alpha / \beta=4 / 1\right.$, Schäfer et al., 1984).

Two binding-sites were characterized on isolated $\beta$ 
subunit of Rhodospirillumm rubrum $\mathrm{F}_{1}$. One nucleotide binding-site is a $\mathrm{M}_{\mathrm{g}}{ }^{2+}$ independent "high affinity site" $\left(K_{\mathrm{D}}=4.4 \mu M\right.$ for ATP and 6.7 $\mu M$ for ADP). The second is a $\mathrm{Mg}^{2+}$ dependent "low affinity site" $\left(K_{\mathrm{D}}=200 \mu M\right)$ which seems to contain also the binding-site for $P_{i}$ (Gromet-Elhanan and Khananshvili, 1984; Khananshvili and Gromet-Elhanan, 1985).

3'-0(4-Benzoyl)benzoyl ADP (Bz-ADP) interacts with ATP sites of heat-activated $\mathrm{CF}_{1}$. Complete inactivation was shown to occur upon binding of 2.45 $\mathrm{mol} \mathrm{Bz-ADP} / \mathrm{mol} \mathrm{CF}_{1}$. Bz-ADP was bound only on subunits $\beta$ of $C F_{1}$, with the isolated enzyme, (Bar-Zvi and Shavit, 1984) or $\alpha$ and $\beta$ subunits with the membrane bound enzyme (Bar-Zvi et al., 1983).

Enzymatic mechanism and role of nucleotide binding-sites. A recent review of Strotmann (1985) is available on this subject. We want to underline some outstanding aspects of this open question.

It is accepted that ATP is formed from ADP and is not the result of the direct photophosphorylation of AMP by $\mathrm{CF}_{1}$ (Horner et al., 1983). Yet the elucidation of partial reactions of photophosphorylation may be complicated by side enzyme activities (Feldman and Sigman, 1984).

The three alternating sites model, developed by Bоyer (Gresser et al., 1982) explains many experiments, especially those concerning the increase of water oxygen incorporation in ATP released at low ADP concentration (Kohlbrenner and Boyer, 1983; Stroop and Boyer, 1985) and increase of the off constant of ADP and $\mathrm{P}_{i}$ on one site by ATP binding on another site (O'Neal and Boyer, 1984). The non-energy requirement of the reaction $\mathrm{ADP}+\mathrm{P}_{\mathrm{i}} \rightarrow \mathrm{ATP}$, which has been proposed, seems to be confirmed by the synthesis of ATP from the bound ADP and medium $P_{i}$ on isolated $C_{1}$ (Feldman and Sigman, 1982) or on a completely uncoupled ATP-synthetase (Feldman and Sigman, 1983). Contrarily, $\mathrm{P}_{\mathrm{i}}: \mathrm{H}_{2} \mathrm{O}$ oxygen exchange could indicate that there is an energy requirement for the reversible cleavage of the enzyme bound ATP (Shermann and Wimmer, 1983).

The use of adenosine 5'(0-3-thiotriphosphate) (ATP $y \mathrm{~S}$ ) with thermophilic bacterium $\mathrm{TF}_{1}$ has revealed that hydrolysis of ATP $\gamma \mathrm{S}$ occurs with inline nucleophilic displacement (Kagawa et al., 1984), which excludes possible pathways of ATP synthesis via a phosphorylated intermediate.

Several studies have also underlined the importance of the stereochemistry to elucidate the mechanism of ATP synthesis or hydrolysis, as is the case of ATP metal complexes. Experiments of Kagawa et al. (1984) show that the true substrate for ATP hydrolysis by $\mathrm{TF}_{1}$ is the $\Delta \beta \gamma$ bidentate ATP- $\mathrm{Mg}$ complex while Frash and Selman (1982) propose the substrate of photophosphorylation catalyzed by $\mathrm{CF}_{1}$ be the $\Lambda$ epimer of the bidentate metal-ADP complex.
Service de Biophysique,

CEN Saclay

91191 Gif sur Yvette Cedex,

France

J. M. GAlmiche*

G. Girault

C. LEMAIRE

\section{REFERENCES}

Abbott, M. S., J. J. Czarnecki and B. R. Selman (1984) Localization of the high-affinity binding site for ATP on the membrane-bound chloroplast ATP synthase. J. Biol. Chem. 259, 12 271-12 278.

Akey, C. W., R. H. Crepeau, S. D. Dunn, R. E. McCarty and S. J. Edelstein (1983) Electron microscopy and single molecule averaging of subunit-deficient $F_{1}$-ATPases from Escherichia coli and spinach chloroplasts. EMBO J. 2, 1409-1415.

Alt, J., P. Winter, W. Sebald, J. G. Moser, R. Schedel, P. Westhoff and R. G. Herrmann (1983) Localization and nucleotide sequence of the gene for the ATP synthase proteolipid subunit on the spinach plastid chromosome. Current Genet 7, 129-138.

Amzel, L. M., M. McKinney, P. Narayanan and P. L. Pedersen (1982) Structure of the mitochondrial F1 ATPase at 9 A resolution. Proc. Natl. Acad. Sci. 79, $5852-5856$.

Anthon, G. E. and A. T. Jagendorf (1983) Effect of methanol on spinach thylakoid ATPase. Biochim. Biophys. Acta 723, 358-365.

Anthon, G. E. and A. T Jagendorf (1984) Methanolinduced release of tightly bound adenine nucleotides from thylakoid-associated CF1. Biochim. Biophys. Acta 766, 354-362.

Bar-Zvi, D., M. Tiefert and N. Shavit (1983) Interaction of the chloroplast ATP synthetase with the photoreactive nucleotide $3^{\prime}-0-(4$ benzoyl) benzoyl adenosine $5^{\prime}$-diphosphate. FEBS Lett. 160, 233-238.

Bar-Zvi, D. and N. Shavit (1984) Photoaffinity labeling of soluble chloroplast adenosine 5'-triphosphate with 3'-0 (4 benzoyl) benzoyl ADP. Biochim. Biophys. Acta 765. $340-346$

Berzborn, R. J., P. Roos and G. BonneKamp (1984) Stoichiometry and function of the $\delta$-subunit of CF1. In Advances in Photosynthesis Research, Vol. II, pp. 587-590. (Edited by C. Sybesma). Martinus Nijhoff/D. W. Junk Publishers, The Hague.

Bickel-Sandkötter, S. (1983) Loose and tight binding of adenine nucleotides by membrane-associated chloroplast ATPase. Biochim. Biophys. Acta 723, 71-77.

Bruist, M. and G. Hammes (1981) Further characterization of nucleotide binding sites on chloroplast coupling factor one. Biochemistry 20, 6298-6305.

Casadio, R. and B. A. Melandri (1984) On the regulation of the ATPase activity in chromatophores of $R$ hodopseudomonas sphaeroides. In $H^{+}$-ATPsynthase: Structure, Function, Regulation. ICSU Press. In Press.

Cerione, R. and G. Hammes (1981) Nucleotide interactions with the dicyclohexylcarbodiimide sensitive adenosine triphosphatase from spinach chloroplasts. Biochemistry 20, 3359-3365.

Cerione, R. A., R. E. McCarty and G. Hammes (1983) Spatial relationships between specific sites on reconstituted chloroplast proton adenosine triphosphatase and the phospholipid vesicle surface. Biochemistry 22, 769-776.

Cotton, N. P. J. and J. B. Jackson (1983) Titrations of ATP synthesis with uncoupling agents do not provide evidence of localised high energy intermediates in electron transport phosphorylation in bacterial chro- 
matophores. FEBS Lett. 161, 93-99.

Czarnecki, J. J., M. S. Abbott and B. R. Selman (1982) Photoaffinity labeling with 2-azido-adenosinediphosphate of a tight nucleotide binding site on chloroplast coupling factor. 1. Proc. Natl. Acad. Sci. USA 79, $7744-7748$.

Czarnecki, J. J., M. S. Abbott and B. R. Selman (1983) Localization of the tight ADP-binding site on the membrane-bound chloroplast coupling factor one. Eur. J. Biochem. 136, 19-24.

Czarnecki, J. J. (1984) Tautomerism of 2-azidoadenosine nucleotides. Effects on enzyme kinetics and photoaffinity labeling. Biochim. Biophys. Acta 800, $41-51$.

Davenport, J. and R. E. McCarty (1984) An analysis of proton fluxes coupled to electron transport and ATP synthesis in chloroplast thylakoids. Biochim. Biophys. Acta 766, 363-374.

Deno, H., K. Shinozaki and M. Sugiura (1983) Nucleotide sequence of tabacco chloroplast gene for the subunit of proton translocating ATPase. Nucleic Acids Res. 11, 2185-2191.

Deno, H. and M. Sugiura (1984) Homology between the $\alpha$ and $\beta$ subunits of chloroplast and bacterial proton translocating ATPase. FEBS Lett. 172, 209-211.

Dewey, T. G, and G. G. Hammes (1981) Steady state kinetics of ATP synthesis and hydrolysis catalyzed by reconstituted chloroplast coupling factor. J. Biol. Chem. 256, 8941-8946.

Dilley, R. A. and U. Schreiber (1984) Correlation between membrane-localized protons and flash-driven ATP formation in chloroplast thylakoids. $J$. Bioenerg. Biomemb. 16, 173-193.

Faludi-Daniel, A., O. Schmidt, A. Szczepaniak and $O$. Machold (1983) Distribution of characteristic membrane proteins in granum and stroma thylakoids. Eur. J. Biochem. 131, 567-570.

Feldman, R. I. and D. S. Sigman (1982) The synthesis of enzyme-bound ATP by soluble chloroplast coupling factor. 1. J. Biol. Chem. 257, 1676-1683.

Feldman, R. I. and D. S. Sigman (1983) The synthesis of ATP by the membrane-bound ATP synthase complex from medium ${ }^{32} \mathrm{P}_{\mathrm{i}}$ under completely uncoupled conditions. J. Biol. Chem. 258, 12178-12183.

Feldman, R. I. and D. S. Sigman (1984) Enzymatic activities in thylakoid membranes which form medium $\left({ }^{32} \mathrm{P}\right) \mathrm{NDP}$ and $\left({ }^{32} \mathrm{P}\right)$ ATP from ${ }^{32} \mathrm{Pi}$. Eur. J. Biochem. 143, 583-588.

Finel, M., M. Rubinstein and U. Pick (1984) Preparation of an $\epsilon$-deficient chloroplast coupling factor 1 having a high ATPase activity. FEBS Lett. 166, 85-89.

Flores, S. and D. R. Ort (1984) Investigation of the apparent inefficiency of the coupling between photosystem II electron transfer and ATP formation. Biochim. Biophys. Acta 766, 289-302.

Frasch, W. D. and B. R. Selman (1982) Mechanism of photophosphorylation catalyzed by chloroplast coupling factor 1. Stereochem. Biochem. 21, 3636-3643.

Frei, R., A. Binder and R. Bachofen (1984) Respiration in energy-transducing membranes of the thermophilic cyanobacterium Mastigocladus laminosus. II oxidative phosphorylation. Biochim. Biophys. Acta 765, 247-252.

Furuno, T., A. Ikegami, H. Kihara, M. Yoshida and Y. Kagawa (1983) Small-angle X-ray scattering study of adenosine triphosphatase from thermophilic bacterium PS3. J. Mol. Biol. 170, 137-153.

Girault, G., J. M. Galmiche, C. Lemaire and O. Stulzaft (1982) Binding and exchange of nucleotides on the chloroplast coupling factor CF1. The role of magnesium. Eur. J. Biochem. 128, 405-411.

Gräber, P., U. Junesch and G. H. Schatz (1984)
Kinetics of proton-transport-coupled ATP synthesis in chioroplasts. Activation on the ATPase by an artificially generated $\Delta \mathrm{pH}$ and $\Delta \psi$. Ber. Bunsenges. Phys. Chem. 88, 599-608.

Gresser, M. J., J. A. Myers and P. D. Boyer (1982) Catalytic site cooperativity of beef heart mitochondrial F1 adenosine triphosphatase. J. Biol. Chem. 257. 12030-12038.

Gromet-Elhanan, Z. and D. Khananshvili (1984) Characterization of two nucleotide binding sites on the isolated reconstitutively active $\beta$ subunit of the Fo.F1 ATP synthase. Biochemistry 23, 1022-1028.

Hallick, R. B. (1984) Identification and partial DNA sequence of the gene for the subunit of the ATP synthase complex of Chlamydomonas reinhardii chloroplast. FEBS Lett. 177, 274-276.

Hangarter, R. P. and N. E. Good (1984) Energized state responsible for adenosine 5 '-triphosphate synthesis in preilluminated chloroplast lamellae. Biochemistry $\mathbf{2 3}$, 122-130.

Haraux, F. and Y. de Kouchkowsky (1983) The energy-transduction theories: a micro-chemiosmotic approach in thylakoids. Physiol. Veg. 21, 563-576.

de Heij, H. T., A. G. Jochemsen, P. Th. J. Willemsen and G. S. P. Groot (1984) Protein synthesis during chloroplast development in Spirodela oligorhiza. Eur. J. Biochem. 138, 161-168.

Hitchens, G. D. and D. B. Kell (1983) Uncouplers can shuttle between localized energy-coupling sites during photophosphorylation by chromatophores of Rhodopseudomonas capsulata N.22. Biochem. J. 212, 25-30.

Hollemans, M., M. J. Runswick, I. M. Fearnley and J. E. Walker (1983) The Sites of labeling of the $\beta$-subunit of Bovine mitochondrial F1-ATPase with 8-azido ATP. J. Biol. Chem. 258, 9307-9313.

Hong, Y. Q. and W. Junge (1983) Localized or delocalized protons in photophosphorylation? On the accessibility of the thylakoid lumen for ions and buffer. Biochim. Biophys. Acta 722, 197-208.

Hoppe, J. and W. Sebald (1984) The proton conducting Fo-part of bacterial ATP synthases. Biochim. Biophys. Acta 768, 1-27.

Horner, R. D., J. P. Froehlich and E. N. Moudrianakis (1983) Initial products of photophosphorylation with AMP and $\left({ }^{32} \mathrm{P}\right) \mathrm{Pi}$. J. Biol. Chem. 258, 5618-5622.

Huttly, A. K. and J. C. Gray (1984) Localisation of genes for four ATP synthase subunits in pea chloroplast DNA. Mol. Gen. Genet. 194, 402-409.

Junge, W., Y. Q. Hong, L. P. Qian and A. Viale (1984) Cooperative transient trapping of photosystem II protons by the integral membrane portion (CFo) of chloroplast ATP-synthase after mild extraction of the four subunit catalytic part (CF1). Proc. Natl. Acad. Sci. USA 81, 3078-3082

Kagawa, Y., M. Yoshida, H. Kihara and V. R. Ramakrishnans (1984) Active site in proton translocating ATPase. In Frontiers in Bio-organic Chemistry and Molecular Biology (Edited by Yu. Ovchinnikov). Elsevier Science Publishers B.V., Amsterdam. In press.

Kagawa, Y. (1984) A new model of proton motive ATP synthesis: Acid-base cluster hypothesis. J. Biochem. 95. 295-298.

Kanazawa, H., T. Kayano, T. Kiyasu and M. Futai (1982) Nucleotide sequence of the genes for $\beta$ and $\epsilon$ subunits of proton-translocating ATPase from Escherichia coli. Biochem. Biophys. Res. Comm. 105, 1257-1264.

Kanazawa, H., T. Noumi, N. Oka and M. Futai (1983a) Intracistronic mapping of the defective site and the biochemical properties of subunit mutants of Escherichia coli $\mathrm{H}^{+}$-ATPase: correlation of structural domains with functions of the subunit. Arch. Biochem. 
Biophys. 227, 596-608.

Kanazawa, H., T. Noumi, M. Futai and T. Nitta (1983b) Escherichia coli mutants defective in the subunit of proton-translocating ATPase: intracistronic mapping of the defective site and the biochemical properties of the mutants. Arch. Biochem. Biophys. 223, 521-532.

Ketcham, S. R., J. W. Davenport, K. Warncke and R. E. McCarty (1984) Role of the $\gamma$ subunit of chloroplast coupling factor 1 in the light-dependent activation of photophosphorylation and ATPase activity by dithiothreitol. J. Biol. Chem. 259, 7286-7293.

Khananshvili, D. and Z. Gromet-Elhanan (1982) Isolation and purification of an active $\gamma$ subunit of the Fo.F1-ATP synthase from chromatophores membranes of Rhodospirillum rubrum. The role of $\gamma$ in ATP synthesis and hydrolysis as compared to proton translocation. J. Biol. Chem. 257, 11377-11383.

Khananshvili, D. and Z. Gromet-Elhanan (1984) Demonstration of two binding sites for ADP on the isolated $\beta$-subunit of the Rhodospirillum rubrum RrFo.F1 ATP synthase. FEBS Lett. 178, 10-14.

Khananshvili, D. and Z. Gromet-Elhanan (1985) Characterization of an inorganic phosphate binding site on the isolated, reconstitutively active $\beta$ subunit of the Fo.Fl-ATP synthase. Biochemistry. In press.

Klein-Hitpass, L. and R. J. Berzborn (1984) Accessibility and function of CFo-subunits in chloroplast thylakoids. In Advances in Photosynthesis Research (Edited by C. Sybesma), Vol. II, pp. 563-566. Martinus Nijhoff/Dr. W. Junk Publishers, The Hague.

Kohlbrenner, W. E. and P. D. Boyer (1983) Probes of catalytic site cooperativity during catalysis by the chloroplast adenosine triphosphate and the adenosine triphosphate synthase. J. Biol. Chem. 258, 10881-10886.

Krebbers, E. T., I. M. Larrinua, L. McIntosh and L. Bogorad (1982) The maize chloroplast genes for the $\beta$ and $\epsilon$ subunits of the photosynthetic coupling factor CF1. Nucleic Acids Res. 10, 4985-5002.

Laszlo, J. A., G. M. Baker and R. A. Dilley (1984) Chloroplast thylakoid membrane protein having buried amine buffering groups. Biochim. Biophys. Acta 764, 160-169.

Lemaire, C.. J. M. Galmiche and G. Girault (1984) Flash-induced ATP synthesis in pea chloroplasts and open cells of Chlamydomonas reinhardii CW-15. In Third European Bioenergetics Conference, short reports, Congress edition. Vol. 3A, pp. 245-246.

Lubberding, H. J., G. Zimmer, H. S. van Walraven, J. Schrickx and R. Kraayenhof (1983) Isolation, purification and characterization of the ATPase complex from the thermophilic Cyanobacterium synechococus 6716. Eur. J. Biochem. 137, 95-99.

Merchant, S., S. L. Shaner and B. R. Selman (1983) Molecular weight and subunit stoichiometry of the chloroplast coupling factor 1 from Chlamydomonas reinhardii. J. Biol. Chem. 258, 1026-1031.

Merchant, S. and B. R. Selman (1983) Identification of the $\alpha$ and $\beta$ subunits of the chloroplast coupling factor one in Chlamydomonas reinhardii. Eur. J. Biochem. 137, 373-376.

Mills, J. D. and P. Mitchell (1984) Thiol modulation of the chloroplast protonmotive ATPase and its effect on photophosphorylation. Biochim. Biophys. Acta 764, 93-104.

Moase, E. H. and B. R. Green (1981) Isolation and properties of chloroplast coupling factor from wheat. Eur. J. Biochem. 119, 145-150.

Moroney, J. V., L. Lopresti, B. F. McEwen, R. E. McCarty and G. G. Hammes (1983) The Mr-value of chloroplast coupling factor 1. FEBS Lett. 158, 58-62.

Moroney, J. V., C. S. Fullmer and R. E. McCarty (1984) Characterization of the cysteinyl-containing peptides of the $y$ subunit of coupling factor 1. J. Biol. Chem. 259, 7281-7285.

Müller, H., H. Neufang and K. Knobloch (1983) Kinetic studies on the membrane bound and the purified coupling factor-ATPase from Rhodopseudomonas sphaeroides. Arch. Biochem. Biophys. 224, 283-289.

Nalin, C. M. and R. E. McCarty (1984) Role of a disulfide bond in the $\gamma$ subunit in activation of the ATPase of chloroplast coupling factor 1.J. Biol. Chem. 259, 7275-7280.

Nawroth, T., H. Conrad, J. Vienken and K. Dose (1983) Neutron small angle scattering of matched proteoliposomes with incorporated Fo-F1. ATPase complex from Rhodospirillum rubrum FR 1. HoppeSeyler's Z. Physiol. Chem. 364, 923-931.

Nelson, N. and S. Cidon (1984) New molecular aspects of energy-transducing protein complexes. J. Bioenerg. Biomembr. 16, 11-36.

O'Neal, C. C. and P. D. Boyer (1984) Assessment of the rate of bound substrate interconversion and of ATP acceleration of product release during catalysis by mitochondrial adenosine triphosphatase. J. Biol. Chem. 259, 5761-5767.

O'Shea, P.S. and M. Thelen (1984) On the logic of the application of double inhibitor titrations for the elucidation of the mechanisms of energy coupling. FEBS Lett. 176, 79-82.

Patrie, W. J. and R. E. McCarty (1984) Specific binding of coupling factor lacking the $\delta$ and $\epsilon$ subunits to thylakoids. J. Biol. Chem. 259, 11121-11128.

Pick, U., K. Gounaris, A. Admon and J. Barber (1984) Activation of the CFo-CF1 ATP synthase from spinach chloroplasts by chloroplast lipids. Biochim. Biophys. Acta 765, 12-20.

Pick, U. and M. Finel (1983) Detection of conformational changes in chloroplast coupling factor 1 by 8-anilino-1-naphthalene-sulphonate fluorescence changes. Eur. J. Biochem. 135, 559-567.

Richter, M. L., W. J. Patrie and R. E. McCarty (1984) Preparation of the subunit and $\epsilon$ subunit-deficient chloroplast coupling factor 1 in reconstitutively active forms. J. Biol. Chem. 259, 7371-7373.

Rodermel, S. R. and L. Bogorad (1985) Maize plastid photogenes: mapping and photoregulation of transcript levels during light-induced development. J. Cell Biology. $100,463-476$.

Rott, R. and N. Nelson (1984) Conservation and organization of subunits of the chloroplast proton ATPase complex. In Advances in Photosynthesis Research (Edited by C. Sybesma), Vol. II, pp. 501-510. Martinus Nijhoff/Dr W. Junk Publishers, The Hague.

Rumberg, B. and U. Becher (1984) Multiple $\Delta \mathrm{pH}$ control of $\mathrm{H}^{+}$-ATP synthase function in chloroplasts. In Workshop $H^{+}-A T P$ Synthase: Structure, Function Regulation. ICSU Press. In press.

Satre, M. and G. Zaccai (1979) Small angle neutron scattering of Escherichia coli BF1-ATPase. FEBS Lett. 102, 244-248.

Schäfer, H. J., P. Scheurich, G. Rathgeber, K. Dose and Y. Kagawa (1984) Photoaffinity labeling of the coupling factor 1 from the thermophilic bacterium PS 3 by 8-azido ATP. FEBS Lett. 174, 66-70.

Schreiber, U. (1984a) ATP-induced increase in chlorophyll fluorescence characterization of rapid and slow induction phases. Biochim. Biophys. Acta 767, 70-79.

Schreiber, H. (1984b) Comparison of ATP-induced and DCMU-induced increases of chlorophyll fluorescence. Biochim. Biophys. Acta 767, 80-86.

Schumann, J. (1984) A study on the exchange of tightly bound nucleotides on the membrane-associated chloroplast ATP synthase complex. Biochim. Biophys. Acta 766, 334-342. 
Selman-Reimer, S., M. Finel, U. Pick and B. R. Selman (1984) Partial characterization of the chloroplast coupling factor 1 from the halotolerant alga Dunaliella bardawil. Biochim. Biophys. Acta 764, 138-147.

Shahak, Y. (1985) Differential effect of thiol oxidants on the chloroplast $\mathrm{H}^{+}$-ATPase in the light and in the dark. J. Biol. Chem. 260, 1459-1464.

Sherman, P. A. and M. J. Wimmer (1983) Kinetic effects of Chemical and physical uncoupling on the energy-transducing ATPase from spinach chloroplasts. Eur. J. Biochem. 136, 539-543.

Shinozaki, K., H. Deno, A. Kato and M. Sugiura (1983) Overlap and cotranscription of the genes for the beta and epsilon subunits of tobacco chloroplast ATPase. Gene 24, 147-155.

Snyder, B. and G. G. Hammes (1984) Structural mapping of chloroplast coupling factor. Biochemistry 23 , 5787-5795.

Stroop, S. D. and P. D. Boyer (1985) Characteristics of the chloroplast ATP synthase as revealed by reaction at low ADP concentrations. Biochemistry. In press.

Strotmann, H. (1985) Evaluation of results on nucleotide binding sites of the ATPase complex. Encyclopedia of Plant Physiology, New Series. In press.

Süss, K. H. and R. Manteuffel (1983) The chloroplast ATP synthetase consists of the subunits, $\alpha, \beta, \gamma, \delta, \epsilon$ and proteolipid only. FEBS Lett. 153, 134-140.

Tiedge, H., H. Lünsdorf, G. Schäfer and H. U. Schairer (1984) Electron microscopic approaches to the quaternary structure of $\mathrm{F} 1$ and $\mathrm{CF} 1$. In Third European Bioenergetics Conference, short reports, Vol. 3A, pp. 31-32.

Tybulewicz, V. L. J., G. Falk and J. E. Walker (1984) Rhodopseudomonas blastica atp operon nucleotide sequence and transcription. J. Mol. Biol. 179, 185-214.

Vallejos, R. H., J. L. Arana and R. A. Ravizzini (1983) Changes in activity and structure of the chloroplast proton ATPase induced by illumination of spinach leaves. J. Biol. Chem. 258, 7317-7321. van der Bend, R. L., J. B. W. J. Cornelissen, J. A. Berden and $K$. van Dam (1984) Factors defining the functional coupling of bacteriorhodopsin and ATP synthase in liposomes. Biochim. Biophys. Acta 767, 87-101.

van Walraven, H. S., M. Gravesen and R. Kraayenhof (1984) Purification of a high molecular weight membrane protein by fast protein liquid chromatography: the ATPase complex of a thermophilic cyanobacterium. J. Biochem. Biophys. Meth. 9, 163-169.

Walker, J. E., M. Sarastc and N. J. Gay (1984) Nucleotide sequence, regulation and structure of ATP synthase. Biochim. Biophys. Acta 768, 164-200.

Westerhoff, H. V., B. A. Melandri, G. Venturoli, G. F. Azzone and D. B. Kell (1984) A minimal hypothesis for membrane-linked free-energy transduction. The role of independent, small coupling units. Biochim. Biophys. Acta 768, 257-292.

Woessner, J. P., A. Masson, E. H. Harris, P. Bennoun, N. W. Gillham and J. E. Boynton (1984) Molecular and genetic analysis of the chloroplast ATPase of Chlamydomonas. Plant Mol. Biol. 3, 177-190.

Yoshida, M. and W. S. Allison (1983) Modulation of ADP and $\mathrm{Mg}^{2+}$ of the inactivation of the F1-ATPase from the thermophilic bacterium, PS 3 , with dicyclohexylcarbodiimide. J. Biol. Chem. 258, 14407-14412.

Younis, H. M., G. Weber and J. S. Boyer (1983) Activity and conformational changes in chloroplast coupling factor induced by ion binding: formation of a magnesium-enzyme phosphate complex. Biochemistry 22, 2505-2512.

Zurawski, G., W. Bottomley and P. R. Whitefeld (1982) Structures of the genes for the $\beta$ and $\epsilon$ subunits of spinach chloroplast ATPase indicate a dicistronic mRNA and an overlapping translation stop/start signal. Proc. Natl. Acad. Sci. USA 79, 6260-6264.

Zurawski, G. and M. T. Clegg (1984) The barley chloroplast DNA atp BE, trn M2 and trn V1 loci. Nucleic Acids Res. 12, 2549-2559. 